\title{
AULAS PARA TURMAS-PILOTO: INTERFACES EM DIDÁTICA E ESTÁGIO SUPERVISIONADO EM BIOLOGIA \\ LESSONS TO PILOT CLASSES: INTERFACES BETWEEN DIDATICS AND SUPERVISED TRAINING IN BIOLOGY
}

\author{
Maiza Taques Margraf ALTHAUS* \\ Marcela Teixeira GODOY ${ }^{* *}$
}

Uma experiência só faz sua irrupção quando está sendo dita. Se não for dita é, por assim dizer, não-existente. (Hannah Arendt)

\begin{abstract}
Resumo: $O$ presente relato de pesquisa apresenta $o$ desenvolvimento de um trabalho que, por meio de aulas para turmas-piloto, proporcionou um contato de acadêmicos com alunos antes de se adentrar no campo de estágio. A pesquisa descrita foi realizada no ano de 2005, com 13 acadêmicos do terceiro ano do curso de Ciências Biológicas da Universidade Estadual de Ponta Grossa (UEPG), no Paraná. Os principais objetivos foram: avaliar o impacto resultante da vivência das aulas para turmas-piloto na formação docente e verificar se alguns dos encaminhamentos teórico-metodológicos trabalhados nas disciplinas de Didática e Estágio Supervisionado em Biologia revelavam-se nos procedimentos dos acadêmicos durante a realização da prática em questão. Para tanto, utilizou-se a abordagem de pesquisa qualitativa, de natureza interpretativa. A metodologia abrangeu três momentos para registro e análise do material empírico, obtido através do trabalho com a tematização da prática: ação, reflexão, ação. Os principais resultados apontam
\end{abstract}

* Mestre em Educação pela Universidade Estadual de Ponta Grossa - E-mail: professoramaiza@ uol.com.br www.maiza.com.br

${ }^{* *}$ Mestre em Tecnologia e Desenvolvimento pela Universidade Tecnológica Federal do Paraná E-mail biogodoy@yahoo.com.br 
Aulas para turmas-piloto: interfaces em didática e estágio supervisionado...

para uma melhora significativa nas aulas ministradas pelos acadêmicos após a reflexão sobre a prática, pois possibilitaram aos licenciandos a análise do trabalho docente frente à classe, permitindo o aprimoramento das práticas de ensino.

Palavras-Chave: Estágio supervisionado. Didática. Formação de professores.

\begin{abstract}
This research report presents the development of a work which provided this kind of contact before the students' training by teaching lessons to pilot classes. The research was developed in 2005 by 13 trainees from the $3^{\circ}$ serie of Biologycal Sciences course at Universidade Estadual de Ponta Grossa (UEPG) - State of Paraná. The main objectives were: to evaluate the impact for academic students formation as a result of the lessons taught to pilot classes and verify if some theoretical and methodologic procedures worked during Didactics and Biology Teaching Practice lessons have appeared during the mentioned practice. For this purpose a qualitative approach research was used, through an interpretative nature. The methodology for registration and analysis of the empirical material collected was divided into three moments: action, reflexion, action. The results pointed to significative improvement in lessons taught by students after the reflexion about their practice because it permited an analysis of the teaching work in front of the classes, allowing teaching practices improvement.
\end{abstract}

Keywords: Supervised training. Didactics. Teachers formation.

\title{
INTRODUÇÃO
}

O trabalho com os acadêmicos da terceira série do Curso de Licenciatura em Ciências Biológicas da UEPG (turno vespertino) denotou que eles apresentavam dificuldades quanto à organização da 
ação docente, bem como certa resistência em se assumirem enquanto futuros professores. Durante o ano de 2005, ao frequentarem as aulas das disciplinas de Didática e Estágio Supervisionado em Biologia, ministradas, respectivamente, pelas autoras deste artigo, os licenciandos, quando questionados sobre os conteúdos pertinentes às disciplinas, mostraram certa apatia acadêmica. Em sua maioria, revelaram que não pretendiam atuar no ensino de Ciências e/ou Biologia, mas sim como biólogos. Na UEPG, Althaus $(1997$, p.6) já havia sinalizado o problema da constituição da identidade dos licenciandos como futuros professores: "O despertar pedagógico começa a se manifestar apenas no final dos cursos, no momento em que os alunos realizam estágios nas escolas". Procurou-se, então, desenvolver uma pesquisa que, através da proposição de aulas para turmas-piloto, fosse voltada a investigar e suprir tais dificuldades, oportunizando assim uma vivência didática aos acadêmicos.

Outro fator que contribuiu para a realização da pesquisa que motivou a produção deste trabalho foi a vivência das autoras como docentes e pesquisadoras da referida instituição, compromissadas com o desenvolvimento de pesquisas na Licenciatura, além do fato de confiarem em uma concepção de ensino baseada na interdependência entre as disciplinas de Didática e Estágio Supervisionado em Biologia. Como afirma Andrade (1995), para a superação do modelo fragmentado e compartimentado de estrutura curricular pautada no isolamento dos conteúdos trabalhados, essa interdependência é fundamental.

Diante disso, a problemática central que norteou o estudo em tela direcionou-se para a investigação dos fatores expostos.

Ao dar-se relevo à perspectiva interdisciplinar, partiu-se da premissa de que as atividades práticas de docência, propostas aos licenciandos de acordo com as ementas curriculares, não poderiam ser concretizadas sem levar em conta um conjunto de variáveis que agissem e interagissem na dinâmica de uma situação real de ensino/ aprendizagem. Em outras palavras, foram apresentados e discutidos outros aspectos ligados à gestão de classe e ao contexto no qual se desenvolve $o$ ato profissional de ensino, incluindo-se também os conflitos internos e externos à sala de aula, tais como as concepções cognitivas dos alunos, seus projetos pessoais e as visões dos professores. (LENOIR, 1998).

Foi proposto aos licenciandos, enquanto estratégia para su- 
Aulas para turmas-piloto: interfaces em didática e estágio supervisionado...

peração e enfrentamento das dificuldades então diagnosticadas, o desenvolvimento de uma modalidade didática denominada aulas para turmas-piloto. Krasilchik (1987) descreve essa proposta como sendo a organização de turmas com alunos convidados das escolas de Ensino Médio e Fundamental para assistirem a um conjunto de aulas desenvolvidas na universidade.

Alguns aspectos sustentavam a opção por tal modalidade e, consequentemente, mobilizavam o desafio da continuidade da pesquisa. Primeiramente, os licenciandos - que na época estavam na terceira série do curso (2005) - teriam uma atuação pedagógica nas escolas somente no ano seguinte, ou seja, no último ano do curso, por ocasião da realização dos estágios supervisionados. Desse modo, através das aulas para turmas-piloto, seria possível aproximar os licenciandos das práticas de ensino com alunos do ensino fundamental, possibilitandolhes então uma maior bagagem para o enfrentamento dos estágios no ano seguinte. Outro aspecto prendeu-se ao fato da necessidade de convocar os licenciandos para a organização do ensino. Assim, o planejamento e a avaliação constituem-se partes inseparáveis da atuação docente:

Entender a intervenção pedagógica exige situar-se num modelo em que a aula se configura como um microssistema definido por determinados espaços, uma organização social, certas relações interativas, uma forma de distribuir o tempo, um determinado uso dos recursos didáticos, etc. (ZABALA, 1998, p.78).

Para estabelecer os objetivos da pesquisa, recorreu-se à contribuição teórica de Larocca (2005, p.12), ao dizer que "os objetivos avaliativos intencionam a apreciação e a crítica valorativa, exigem do trabalho maior profundidade e análise". Tendo esse intuito de, concomitantemente, investigar avaliando - inclusive a prática pedagógica enquanto responsável pela formação dos referidos futuros professores - definiram-se como objetivos:

- avaliar o impacto resultante da vivência das aulas para turmas-piloto, com base nos conceitos de ação-reflexão-ação trabalhados na formação inicial do professor de Ciências;

- identificar se alguns indicativos dos encaminhamentos teóricometodológicos trabalhados nas disciplinas Didática e Estágio Supervisionado em Biologia revelaram-se nas práticas de ensino dos licenciandos. 
Ao abordar as ações didáticas presentes na organização do trabalho pedagógico, pode-se considerar que é imprescindível a discussão teórica a respeito da aula, aqui compreendida como momento político-pedagógico da prática escolar, como se constatará a seguir.

A necessidade de aprender a ensinar coloca em pauta o planejamento das ações que se pretende articular com os alunos envolvidos no processo. Assim sendo, quando desafiados a observar e acompanhar o desenvolvimento de um conjunto de aulas nas escolas de Ensino Fundamental, os licenciandos, via de regra, deparam-se com uma realidade em que, mais importante do que discutir criticamente o encaminhamento metodológico, é tentar captar a concepção de ensino e de aprendizagem que o professor revela em suas ações. Em outras palavras, se à frente da classe, o professor expõe um conteúdo e do outro lado o aluno copia, tão somente reproduzindo o discurso do professor, muitas vezes desprovido de diálogo, certamente é possível realizar uma leitura crítica das concepções subjacentes a tais práticas.

Quando se propôs a realização das aulas para turmas-piloto, buscou-se apresentar suas razões e contribuições ao processo de formação docente. Porém, os questionamentos dos licenciandos revelavam preocupações extremamente simplistas, como se a organização da ação docente se resumisse em questões puramente técnicas. Suas preocupações direcionavam-se somente em relação aos materiais didáticos, ou aos procedimentos didático-metodológicos. A expressão "dar aulas" fazia-se presente no cotidiano dos licenciandos, ao participarem das aulas das disciplinas citadas.

Wachowicz é oportuna quanto ao uso dessa expressão, ao afirmar:

A redescoberta de que a aula é um texto e tem como instrumentos a palavra e outras linguagens pode esclarecer a concepção de uma aula como a luta pela coerência, desde que o pressuposto fundamental dessa concepção seja o de que uma aula nunca está pronta nem antes nem durante o seu tempo. Portanto, não pode ser dada, mas pode ser feita. (2004, p.24).

Assim sendo, o reducionismo que imperava nas concepções trazidas pelos acadêmicos foi paulatinamente superado pelas discussões teóricas. Rays (2002, p.79) afirma que a concepção de aula pautada 
Aulas para turmas-piloto: interfaces em didática e estágio supervisionado...

numa didática crítica não comporta tão somente um momento pedagógico, mas também um momento político. Segundo o autor,

a aula não tem apenas o educando como interlocutor. A aula tem interlocutores que se colocam no mesmo nível de importância do educando: a ciência, o saber cotidiano, a prática social e a realidade sociocultural [...]. A visão tradicional de aula, que a confunde como transmissão pura e simples de conhecimentos, habilidades e competências, é uma visão político-pedagógica equivocada tanto do ponto de vista didático como do ponto de vista científico.

É sabido também que, durante as atividades de estágio supervisionado, o licenciando é, concomitantemente, aluno e professor. E a constatação e análise das contradições presentes no cotidiano escolar são fundamentais para a aprendizagem da docência. Porém, para que se consolide a transição da concepção de aulas assistidas enquanto licenciandos durante a graduação, para aulas que podem ser planejadas e construídas com os alunos do Ensino Fundamental, é preciso o esforço articulado de todas as disciplinas do currículo acadêmico. Trata-se, isto sim, de um processo de mudança de paradigmas, que não se concretiza isoladamente.

Durante o curso de Licenciatura em Ciências Biológicas, os acadêmicos têm como parte de seu Estágio Curricular Obrigatório, entre outras atividades, o estágio de regência, que Krasilchik (1996) define como aquele em que o estagiário tem a responsabilidade da condução da aula. Para tanto, a autora sugere várias possibilidades de efetivação da prática docente durante o estágio, como minicursos, atividades extra-classe, condução de atividades esparsas como discussões, auxílio na recuperação, etc.

Krasilchik (1996) também apresenta diferentes modalidades didáticas para a condução das aulas, a saber:

Aulas expositivas: têm como principal função informar os alunos. Servem para introduzir um assunto novo, sintetizar um tópico ou comunicar experiências vividas pelo professor.

Discussões: vistas como um sensível progresso nas aulas de Ciências, as discussões são como convites ao raciocínio, envolvendo os estudantes em descobertas científicas além de oportunizar atividades que exigem imaginação e capacidade de raciocínio.

Demonstrações: servem para apresentar aos estudantes técni- 
cas, fenômenos, espécimes, para garantir que um mesmo fenômeno seja visto simultaneamente, ou que o professor queira ganhar tempo.

Aulas práticas: permitem que o aluno tenha contato direto com os materiais, propondo problemas e sugerindo hipóteses.

Excursões: levam os alunos a observarem o sítio onde trabalham e identificar novos problemas, executar tarefas das quais foram incumbidos.

Projetos: são atividades executadas pelo aluno ou pela equipe, com tempo programado, que visam à resolução de um problema e que resultam em relatório, coleções, exposições, enfim, em um produto final concreto.

Entre tais possibilidades, a modalidade "aulas para turma piloto" veio ao encontro do principal interesse das autoras: oportunizar aos acadêmicos uma formação de qualidade. Porém, segundo Krasilchik, deve-se tomar cuidado com a supervalorização desse tipo de procedimento. Todas as partes devem estar cientes de que se trata de uma simulação, pois "há enormes diferenças entre a situação real de um grupo de alunos altamente motivados que vêm à universidade para assistir a um curso e o que realmente acontece nas classes das escolas onde os futuros professores irão trabalhar". (KRASILCHIK, 1996, p.176).

Cientes de tal consideração, a proposta foi encaminhada aos licenciandos, que manifestaram interesse em participar do trabalho, pois o contato com alunos de escolas públicas permitiria uma reflexão sobre o que cada licenciando vivenciou e não somente sobre como deveria ser trabalhado no ano seguinte.

\section{METODOLOGIA}

Treze acadêmicos da terceira série do curso de Licenciatura em Ciências Biológicas da UEPG foram os interlocutores da pesquisa, sendo três do sexo masculino e dez do sexo feminino, com idades compreendidas entre 22 e 25 anos. Na época (2005), nenhum dos licenciandos trabalhava em escolas ou em outras atividades pedagógicas.

Tal opção justifica-se pelo fato de as pesquisadoras serem professoras do referido curso, atuando especificamente nas disciplinas de Didática e Estágio Supervisionado em Biologia, além de confiarem 
Aulas para turmas-piloto: interfaces em didática e estágio supervisionado...

que através do estudo proposto poderiam contribuir para mobilizar os licenciandos para a docência no ensino de Ciências, tendo em vista a resistência deles em se assumirem enquanto futuros professores.

A pesquisa desenvolveu-se na UEPG em parceria com a Escola Estadual Hália Terezinha Gruba, instalada nas dependências do CAIC - Centro de Atenção Integral à Criança - Reitor Álvaro Augusto da Cunha Rocha, durante o ano de 2005. A turma piloto era constituída por 20 alunos de oitava série, entre 13 e 15 anos de idade.

O processo de ação-reflexão-ação (SHON, 1983; NÓVOA, 1992; PÉREZ-GÓMEZ, 1992) fundamentou a metodologia da pesquisa, que abrangeu três momentos para registro e análise do material empírico.

Optou-se, primeiramente, pela observação direta das aulas planejadas e ministradas para turmas-piloto, com registro através de filmagens e fotografias das aulas (ação). Os acadêmicos deveriam, então, ministrar uma aula de Ciências para os alunos do Ensino Fundamental, com vinte minutos de duração, sobre um assunto escolhido pelos próprios alunos da escola através de consulta prévia. Para realizá-la, os acadêmicos foram orientados a procurar aprofundamento teórico nas obras dos principais autores trabalhados durante as aulas conduzidas, bem como o suporte teórico das disciplinas de conhecimento específico do curso. Os alunos da Escola Hália Terezinha Gruba participaram das aulas dos licenciandos nas dependências da UEPG.

Em um segundo momento, de posse do material empírico, deuse a análise e reflexão entre os acadêmicos e professoras sobre as aulas ministradas, para avaliar a vivência inicial (reflexão). O seminário foi adotado como estratégia didática para conduzir a reflexão de maneira mais sistemática, com o intuito de ver e rever a realidade de forma atenta. Também foi realizada a problematização dos resultados obtidos na primeira aula, com o suporte da teoria trabalhada nas disciplinas de Didática e Estágio Supervisionado em Biologia. No terceiro e último momento, quando cada aula foi reavaliada e reorganizada, após reflexão sobre sua prática anterior, os licenciandos ministraram novas aulas (ação) para os alunos na própria escola. Vale dizer que foi concedida autorização verbal da escola para a documentação das imagens.

Quanto à reflexão sobre a prática pedagógica, Valadares (2002, p.199) destaca: "Ao se refletir sobre uma ação deve-se ter claro que essa análise é realizada à luz de um referencial teórico, e assim fica 
evidente a necessidade de uma formação teórica do professor que possibilite o resgate de sua prática".

Por meio da proposta conceitual intitulada tematização da prática, recorreu-se também à contribuição de Weisz (2004, p.123) para fundamentar a opção pelos procedimentos de coleta dos dados. Segundo a autora,

O trabalho de tematização é uma análise que parte da prática documentada para explicitar as hipóteses didáticas subjecentes. Chamamos a este trabalho tematização da prática porque se trata de olhar para a prática de sala de aula como um objeto sobre o qual se pode pensar [...] é um instrumento de formação que vai na direção contrária à da tradicional visão aplicacionista de formação de professores [...]. Para ser tematizada, a prática do professor precisa estar documentada [...]. a mais poderosa de todas as formas de documentação é [...] a gravação da atividade em vídeo. A esta gravação deve-se anexar o relato/reflexão escrito pelo professor, sempre que possível.

Para Weisz, a prática da tematização permite conjugar múltiplos olhares através de discussão sobre a atividade que está sob análise. Assim, a vivência prática através das aulas para turmas piloto constituiu-se mais enquanto um processo de investigação do que um contexto de aplicação. (PÉREZ GÓMEZ, 1992).

Enquanto processo de desenho e intervenção sobre a realidade, a prática é uma atividade criativa, que não pode considerar-se exclusivamente uma atividade técnica de aplicação de produções externas. No diálogo reflexivo que o aluno-mestre mantém com a realidade problemática, cria-se uma nova realidade, novos espaços de intercâmbio, novos marcos de referência, novos significados e novas redes de comunicação. Ao criar uma nova realidade a prática abre um novo espaço ao conhecimento e à experiência, à descoberta, à invenção, à realidade e à diferença. (Idem, p.112)

Em síntese, a abordagem qualitativa, de natureza interpretativa, foi a metodologia escolhida para o desenvolvimento da pesquisa, tendo em vista as considerações acima expressas. 
Aulas para turmas-piloto: interfaces em didática e estágio supervisionado...

\section{RESULTADOS}

Mais uma vez, percebeu-se claramente que o acadêmico sente dificuldade para se desvencilhar de concepções tradicionais do processo ensino-aprendizagem. Em todas as aulas ministradas, a modalidade aula expositiva foi unanimidade entre todos os acadêmicos. Uma vez que não foi exigida esta ou aquela modalidade didática, os acadêmicos tinham autonomia para optar.

Krasilchik (1996) ratifica esta discussão ao dizer que há um decréscimo de atenção dos ouvintes durante a aula expositiva, a qual, segundo a autora, na maioria das vezes é cansativa e pouco contribui para a formação dos alunos.

Em nenhum momento os acadêmicos utilizaram as outras modalidades didáticas discutidas e trabalhadas nas aulas de Didática e de Estágio Supervisionado em Biologia. Ficou claro que, apesar de discutidas e aprofundadas em sala de aula através de leituras e seminários, a concepção de "aula" que predominava no universo pesquisado era a de aula expositiva. A participação dos alunos da escola por meio de debates, questionamentos ou outra forma de interação durante as aulas expositivas não se fez presente, impossibilitando assim uma relação dialógica que também poderia estar presente na modalidade exposição didática.

Por outro lado, a relevância dessa estratégia de ensino não é desconsiderada nesta pesquisa. As palavras de Wachowicz (2001, p.46) ratificam tal posição:

Se o professor conhece sua área, a ponto de explicá-la pelos seus princípios teóricos, então ele pode e deve fazer a exposição. Não qualquer exposição, mal cuidada e sem vida, mas a sua análise teórica e fundamentada do conteúdo, que assim será outro conteúdo, não existente nos livros e outros produtos culturais, mas construído no processo de exposição, chegando a uma síntese nova, porque pensada novamente. Entre outros métodos aos quais chegou a pedagogia atual, cabe a exposição didática, nos momentos de síntese e também nos momentos da síncrese, do trabalho da aprendizagem, este sim, realizado inteiramente pelos estudantes em parceria com o professor, como processo ativo de construção do conhecimento.

Também para Freire (2001, p.96), 
o fundamental é que professor e alunos saibam que a postura deles, do professor e dos alunos, é dialógica, aberta, curiosa, indagadora e não apassivada, enquanto fala ou enquanto ouve. O que importa é que professor e alunos se assumam epistemologicamente curiosos.

Some-se a isso a necessidade de a exposição didática assumir uma postura dialógica pautada no domínio de certas habilidades. Segundo Libâneo (2002, p.75), "o tornar-se professor é uma atividade de aprendizagem e, para isso, são requeridas capacidades e habilidades específicas".

Em relação ao que, classicamente, denominam-se habilidades didáticas, Cunha (1989) defendeu sua tese de doutorado investigando sobre a prática pedagógica dos bons professores. A observação das aulas possibilitou à autora a apreensão dos dados sobre o que faz o bom professor no cotidiano escolar. Nesse processo, categorizou cinco grupos de habilidades de ensino:

- organização do contexto da aula;

- incentivo à participação do aluno;

- tratamento proporcionado à matéria de ensino;

- variação de estímulos;

- uso da linguagem.

As habilidades referenciadas por Cunha foram discutidas teoricamente nas aulas de Didática e Estágio Supervisionado em Biologia, para que os licenciandos pudessem compreender a importância da observação das habilidades no contexto das aulas para as turmaspiloto.

Nas duas primeiras semanas após os acadêmicos haverem ministrado suas primeiras aulas para as turmas-piloto, durante a reflexão em Seminário com a participação das professoras das disciplinas já mencionadas, foram exibidos os vídeos e as fotos das aulas, momento em que foram discutidos vários pontos levantados pelos acadêmicos, dentre os quais se destacam:

- o reconhecimento pelos acadêmicos de seu descaso com as referidas disciplinas;

- a consciência de como isso interferiu negativamente em sua prática inicial;

- a necessidade de rever alguns conceitos teórico/científicos explorados nas aulas, mas agora sob nova perspectiva; 
Aulas para turmas-piloto: interfaces em didática e estágio supervisionado...

- a necessidade de abordar de forma diferenciada os conteúdos ministrados anteriormente em uma nova proposta de aula para as mesmas turmas-piloto;

- a importância da articulação entre as disciplinas de Didática e Estágio Supervisionado em Biologia, pois, segundo os depoimentos coletados, os acadêmicos sentiram-se mais seguros ao perceber objetivos bem traçados e a mesma linguagem em ambas as disciplinas.

Após exaustiva discussão e reflexão sobre as primeiras aulas ministradas, os acadêmicos ministraram, em um segundo momento, novas aulas para as turmas-piloto. Percebeu-se, então, uma evolução conceitual em dois níveis:

(1) Enquanto nas primeiras aulas conduzidas foi perceptível a improvisação e a falta de domínio dos conteúdos específicos abordados, nesse segundo momento percebeu-se o aprofundamento e domínio teórico do conteúdo específico. Apesar de não constituírem foco central do presente trabalho, a insegurança e a falta de aprofundamento dos conteúdos específicos mostraram-se como uma fragilidade do currículo. A falta de integração entre as disciplinas didático-pedagógicas e as de cunho específico constitui uma das condições básicas para qualquer ação significativa na formação inicial. Mas, segundo os acadêmicos pesquisados, nenhuma disciplina de conhecimento específico foi direcionada para atender às necessidades da licenciatura, sendo as disciplinas específicas tratadas em nível de bacharelado. Essa é uma das razões para a dificuldade de fazer a transposição didática.

(2) O outro nível observado refere-se à utilização de diferentes modalidades didáticas: os acadêmicos adotaram várias estratégias observadas em sala de aula, como discussões, experimentos, simulações, e não somente em relação à aula expositiva, vista então como único procedimento nas primeiras aulas. As autoras procuraram fazer com que seus alunos atingissem um nível multidimensional de alfabetização biológica, ou seja, estimularam os estudantes a "aplicar o conhecimento e habilidades adquiridas relacionando-os com conhecimentos de outras áreas para resolver problemas reais". (KRASILCHIK, 1996, p.12). Em outras palavras, a aprendizagem dos estudantes extrapolou a memorização de nomes técnico-científicos (alfabetização nominal), conforme se pode observar através do registro das aulas. Algumas habilidades didáticas, tais como o incentivo 
à participação dos alunos e a habilidade de organizar o contexto da aula, foram melhor exploradas.

A discussão realizada através dos Seminários, que se constituíram em tempo e espaço para reflexão sobre a prática, foi também enriquecida pela possibilidade da partilha, ou seja, todos os licenciandos acompanharam cada aula conduzida, diferentemente dos estágios nos períodos de regências (ou docências), quando a observação e o acompanhamento das aulas se restringem apenas para o professor supervisor técnico (professor regente da escola) e o professor de estágio da Universidade. Em outras palavras, o processo de reflexão foi enriquecido pelo envolvimento de todos os licenciandos nos seminários propostos, com a análise de cada aula ministrada.

$O$ acadêmico deve ter a consciência de que na formação inicial do professor deve-se exigir um trabalho permanente de estudo e reflexão. Ser professor exige a consciência de que a bagagem com a qual se conclui um curso de Licenciatura será sempre insuficiente para o desempenho de sua tarefa em sala de aula.

\section{CONSIDERAÇÕES FINAIS}

A análise empreendida no presente relato de pesquisa colocou em evidência a contribuição das aulas para turmas-piloto para a formação acadêmica dos licenciandos. Tal experiência foi construída a partir do enfrentamento dos desafios e dilemas trazidos pelos licenciandos durante o ano de 2005, através das aulas conduzidas em Didática e Estágio Supervisionado em Biologia. Permitiu, também, tecer algumas considerações a respeito da importância dessa modalidade didática na formação inicial de professores.

As limitações que se encontram nesta pesquisa resultam precisamente das suas características. Se, por um lado, valorizou-se a experiência com aulas para turmas-piloto e a reflexão sobre elas como um elemento importante à formação inicial de professores, por outro lado não deixou de estar presente a marca de sua incompletude, tendo em vista a ausência de diálogo entre as demais disciplinas do curso. Destaca-se, sobremaneira, a relevância do papel da Coordenação de Curso, no que se refere à organização de ações coletivas visando à interdisciplinaridade nas Licenciaturas.

Diante das reflexões aqui expressas e dos dados obtidos na pesquisa relatada, pode-se inferir que: 
Aulas para turmas-piloto: interfaces em didática e estágio supervisionado...

- A experiência desenvolvida pelos licenciandos nas aulas para turmas-piloto está associada às fragilidades que emergem do currículo do curso de Licenciatura - tais como a ausência da relação teoria-prática, conteúdo-forma - que, segundo os acadêmicos, evidenciam-se apenas em algumas disciplinas do curso.

- Nessa experiência, é notória a presença de alguns fatores que evidenciam um certo descompromisso acadêmico, tais como: a falta de empenho inicial em planejar adequadamente as aulas com os subsídios fornecidos pelas disciplinas; a visão reducionista da ação docente, até então voltada quase que exclusivamente ao preparo de uma exposição oral de um tema, sem estudá-lo com afinco, mas apenas confiando no que se domina preliminarmente sobre o mesmo, como se o processo de ensino fosse resultante de uma simples fala apresentada aos alunos.

- A concepção de aprendizagem inicial da docência e as tarefas ligadas ao desempenho dos licenciandos - tais como a interrogação e a reflexão com seus pares (colegas licenciandos) foram parte integrante da referida experiência e contribuíram para uma permanente e produtiva discussão teórico-prática sobre o significado de cada aula vivenciada. Assim, oportunizaram aos acadêmicos o ingresso na quarta série do curso de Licenciatura em Ciências Biológicas com uma bagagem inicial de convivência didática com alunos do Ensino Fundamental. Os acadêmicos interagiram a partir de uma base comum para discussões, uma vez que todos estavam presentes às mesmas aulas, envolvendo-se em cada docência conduzida pelos colegas. Questões que haviam passado despercebidas tanto pelos acadêmicos como pelas docentes tornaram-se claras e passíveis de discussão à medida que as aulas para as turmaspiloto foram transcorrendo.

O potencial da experiência foi muito significativo para ambas as partes - docentes e licenciandos - pois se, de um lado, estes tiveram suas fragilidades expostas, colocadas em discussão para que pudessem mudar os procedimentos, compreendendo que a opção metodológica expressa também a concepção que se tem de ensino e de aprendizagem, por outro lado, as docentes envolvidas puderam repensar, reavaliar e modificar alguns aspectos de sua prática en- 
quanto docentes universitárias.

Soma-se a isso o enriquecimento do trabalho através da tematização da prática, com a gravação das aulas em vídeo e registro em fotos digitais. A possibilidade de cada um ver o seu próprio comportamento docente frente à classe permitiu que os acadêmicos/professores aprimorassem suas posturas didáticas, aperfeiçoando suas práticas de ensino, fato comprovado nas aulas ministradas após a reflexão dos aspectos então considerados frágeis.

A discussão das aulas com os próprios alunos dos cursos de ensino fundamental foi também bastante enriquecedora. A opinião oral e escrita dos alunos da rede pública sobre as aulas ministradas pelos acadêmicos oportunizou a estes uma idéia dos interesses e reações dos estudantes e de sua opinião em relação aos procedimentos compartilhados.

No que diz respeito aos objetivos traçados, constatou-se que o diálogo entre as disciplinas de didática e estágio supervisionado em Biologia contribuiu sobremaneira para o enriquecimento da prática dos futuros professores. Vários indicativos dos encaminhamentos teórico-metodológicos das disciplinas em questão estiveram presentes após o desenvolvimento das primeiras aulas para turmas-piloto, pois como já se mencionou, na primeira experiência a visão que se revelava era de total desarticulação com o que estava sendo trabalhado pelas docentes. Durante todo o processo, os licenciandos tiveram uma visão ampla da integração e do planejamento das citadas disciplinas, o que ratifica a necessidade da interdisciplinaridade entre Didática, Estágio Supervisionado em Biologia e disciplinas de conteúdos específicos.

Por fim, pensando em investigações futuras, a pesquisa deixa margem para outras temáticas que podem ser aprofundadas, tais como as implicações da transposição didática na aprendizagem da docência.

\section{REFERÊNCIAS}

ALTHAUS, M. T. M. Didática: da análise de suas contribuições nos cursos de Licenciatura da Universidade Estadual de Ponta Grossa à análise de suas repercussões na prática pedagógica do professor de escola pública. Dissertação de Mestrado. UEPG, 1997. p.140. 
Aulas para turmas-piloto: interfaces em didática e estágio supervisionado...

ANDRADE, R.C. Interdisciplinaridade: um novo paradigma curricular. In: GOULART, I.B. A educação na perspectiva construtivista: reflexões de uma equipe interdisciplinar. Petrópolis: Vozes, 1995.

CUNHA, M. I. O bom professor e sua prática. Campinas: Papirus, 1989.

FREIRE, P. Pedagogia da autonomia. São Paulo: Paz e Terra, 2001.

KRASILCHIK, M. O professor e o currículo das ciências. São Paulo: Edusp, 1987.

. Prática de ensino de biologia. São Paulo: Harbra, 1996.

LAROCCA, P.; ROSSO, A. J.; SOUZA, A. P. A formulação dos objetivos de pesquisa na pós-graduação em Educação: uma discussão necessária. Revista Brasileira de Pós-Graduação, Brasília, n.3, p.118-133, mar. 2005.

LENOIR, Y. Didática e interdisciplinaridade: uma complementaridade necessária e incontornável. In: FAZENDA, I. (Org.). Didática e interdisciplinaridade. Campinas: Papirus, 1998. p. 45-76.

LIBÂNEO, J. C. Reflexividade e formação de professores: outra oscilação do pensamento pedagógico brasileiro? In: PIMENTA, S. G.; GHEDIN, E (Orgs.). Professor reflexivo no Brasil: gênese e crítica de um conceito. São Paulo: Cortez, 2002. p. 53-79.

NÓVOA, A. (Org.). Os professores e sua formação. Lisboa: Publicações Dom Quixote, 1992.

PÉREZ-GÓMEZ, A . O pensamento prático do professor: a formação do professor como profissional reflexivo. In: NÓVOA, A. (Org.). Os professores e sua formação. Lisboa: Publicações Dom Quixote, 1992. p. 95-114.

RAYS, O. A. O conceito de aula: um dos saberes necessários à práxis pedagógica. In: - (Org.). Educação: ensaios reflexivos. Santa Maria: Pallotti, 2002.

SCHÖN, D. The reflective practitioner. Nova York: Basic Books, 1983.

VALADARES, J. M. O professor diante do espelho: reflexões sobre o conceito de professor reflexivo. In: PIMENTA, S. G.; GHEDIN, E. (Orgs.). Professor reflexivo no Brasil: gênese e crítica de um conceito. São Paulo: Cortez, 2002. p.187-200.

WACHOWICZ, L. A aula dialética: a luta pela coerência. In: ROMANOWSKI, J. P.; JUNQUEIRA, S. R. A; MARTINS, P. L. O. (Orgs.). Conhecimento local e conhecimento universal: a aula, aulas nas ciências naturais e exatas, aulas nas letras e artes. Curitiba: Champagnat, 2004.

310 Olhar de professor, Ponta Grossa, 11(2): 295-311, 2008.
Disponível em <http://www.uepg.br/olhardeprofessor> 
O método dialético na didática da educação superior. In: CASTANHO, S.; CASTANHO, M. E. (Orgs.). Temas e textos em metodologia do ensino superior. São Paulo: Papirus, 2001.

WEISZ, T. O diálogo entre o ensino e a aprendizagem. São Paulo: Ática, 2004.

ZABALA, A. A prática educativa: como ensinar. Porto Alegre: Artmed, 1998.

Enviado em: 04/08

Aceito em: 10/08 